\title{
Warming effects on morphological and physiological performances of four subtropical montane tree species
}

\author{
Yiyong $\mathrm{Li}^{1,2,3} \cdot$ Yue $\mathrm{Xu}^{2,3} \cdot$ Yuelin $\mathrm{Li}^{2,3} \cdot$ Ting $\mathrm{Wu}^{2,3} \cdot$ Guoyi Zhou ${ }^{2,3} \cdot$ Shizhong $\mathrm{Liu}^{2,3} \cdot$ Yanqiong Meng ${ }^{1} \cdot$ \\ Jianan Wang ${ }^{1} \cdot$ Lihong Ling ${ }^{4} \cdot$ Juxiu Liu ${ }^{2,3}$ (D)
}

Received: 10 July 2019 / Accepted: 28 November 2019 / Published online: 10 January 2020

(C) INRA and Springer-Verlag France SAS, part of Springer Nature 2020

\begin{abstract}
- Key message In a downward transplantation experiment, warming stimulated growth and photosynthesis of Schima superba Gardn. et Champ., Syzygium rehderianum Merr. et Perry and Itea chinensis Hook. et Arn. via increased stomatal conductance. Warming had no effect on growth of Machilus breviflora (Benth.) Hemsl., indicating species-specific differences in response to warming.

- Context Climate change has been shown to shift species composition and community structure in subtropical forests. Thus, understanding the species-specific responses of growth and physiological processes to warming is essential.

- Aims To investigate how climate warming affects growth, morphological and physiological performance of co-occurring tree species when they are growing at different altitudes.

- Methods Soils and 1-year-old seedlings of four subtropical co-occurring tree species (Schima superba Gardn. et Champ., Syzygium rehderianum Merr. et Perry, Itea chinensis Hook. et Arn. and Machilus breviflora (Benth.) Hemsl.) were transplanted to three altitudes $\left(600 \mathrm{~m}, 300 \mathrm{~m}\right.$ and $30 \mathrm{~m}$ a.s.1.), inducing an effective warming of $1.0^{\circ} \mathrm{C}$ and $1.5^{\circ} \mathrm{C}$. Growth, morphological, and physiological performances of these seedlings were monitored.

- Results When exposed to warmer conditions, aboveground growth of the four species except $M$. breviflora was strongly promoted, accompanied by increased light-saturated photosynthetic rate and stomatal conductance. Warming also significantly increased concentrations of non-structural carbohydrates in leaves of S. rehderianum and M. breviflora, stems of S. superba and $S$. rehderianum, and roots of $I$. chinensis. However, we did not detect any effect of warming on stomatal length and stomatal density. - Conclusion Our results provide evidence that climate warming could have species-specific impacts on co-occurring tree species, which might subsequently shift species composition and forest structure.
\end{abstract}

Keywords Transplantation $\cdot$ Photosynthesis $\cdot$ Growth $\cdot$ Stomatal traits $\cdot$ Non-structural carbohydrates

Handling Editor: Marcus Schaub

Contribution of co-authors JL and GZ conceived this study; YL, YX, TW, SL, and JW conducted the experiment; YL analyzed the results. All the authors contributed to writing and editing the manuscript.

Juxiu Liu

ljxiu@scbg.ac.cn

1 School of Forestry and Landscape Architecture, Anhui Agricultural University, Hefei 230036, China

2 Key Laboratory of Vegetation Restoration and Management of Degraded Ecosystems, South China Botanical Garden, Chinese Academy of Sciences, Guangzhou 510650, China

3 Center for Plant Ecology, Core Botanical Garden, Chinese Academy of Sciences, Xingke Road 723, Tianhe District, Guangzhou, China

4 Institute of Ecological Engineering, Anhui Dadi Landscape Engineering Corporation, Hefei 230088, China

\section{Introduction}

Global mean temperatures are expected to rise continuously within this century (IPCC 2014). To survive in future climate warming scenarios, tree species must alter morphological and physiological characteristics for adaptation. Tree species which will not be able to adapt to high temperature may even be submitted to local extinction and/or range shifts (Thomas et al. 2004; Jump et al. 2006). These divergent effects of climate warming on co-occurring tree species may result in complex impacts on forest structure and composition (Peñuelas et al. 2007). Thus, understanding the changes in tree performance in response to climate warming is fundamental to predicting forest responses under future climate change. 
Morphological (i.e., specific leaf area, stomatal traits) and physiological (i.e., photosynthesis) traits affecting tree growth may be key components of adaptive strategies for tree development under climate warming (Aspinwall et al. 2016; Trahan and Schubert 2016; Slot and Winter 2017; Rodgers et al. 2018; Wu et al. 2018). Photosynthesis, one of the most important physiological traits determining plant growth, often promoted by warming unless temperature exceeds the thermal threshold or results in soil water deficits (Wertin et al. 2011; Way et al. 2015). Previous studies investigated the effects of warming on photosynthesis through biochemical processes (Salvucci and Crafts-Brandner 2004) and diffusive processes (Prieto et al. 2009; Xu et al. 2016). Stomatal length and density, controlling the gas exchange between atmosphere and leaf tissues, are important morphological traits that can be affected by environmental factors such as soil water availability, light, and warming (Wu et al. 2018). In addition, changes in photosynthesis in response to warming may also be associated with shifts of non-structural carbohydrates (NSCs, soluble sugar, and starch) pools (Tang et al. 2016), which are products of photosynthesis and the major substrates for both primary and secondary plant metabolism. Starch is acting as a carbon reservoir for plant growth and respiration, and soluble sugars serve a critical osmotic function to maintain turgor and vascular transport (Dietze et al. 2014). However, results on NSCs responses of tree species to climate warming are variable. Studies have found that warming can decrease (Wang et al. 2012), increase (Djanaguiraman et al. 2011), or have little effect (Xu et al. 2012) on NSCs concentration in plants. Accordingly, investigating species-specific responses of NSCs in trees experiencing elevated temperature may improve our knowledge of how co-occurring tree species cope with climate warming (Hartmann and Trumbore 2016).

Patterns of tree growth in response to climate warming depend on many factors, including above-mentioned physiological and morphological processes, phenology, water and nutrient availability, functional type, and provenance. Several studies have found positive relationship between growth and temperature in tree species from high latitudes or altitudes (Drake et al. 2015; Anadon-Rosell et al. 2018). For example, Wang et al. (2012) found a significant stimulation of experimental warming on growth of Abies faxoniana in subalpine coniferous forests, which is characterized by low temperatures and a short growing season. However, other studies have indicated that, compared to either boreal or temperate species, tropical species may be near a high temperature threshold for photosynthesis that, if exceeded, will reduce $\mathrm{CO}_{2}$ assimilation and thereby growth (Way and Oren 2010). During the last decades, many inventories in subtropical and tropical regions highlighted that climate warming is modifying forest composition and structure (Sheldon et al. 2011; Zhou et al. 2013, 2014) and result in negative economic effects (Burke et al. 2015). Many of these changes should be consequences of divergent responses of co-occurring tree species to climate warming. Thus, examining whether the effects of warming on subtropical species are species-specific is an essential requirement to better understanding the future state of subtropical forests.

Existing thermal gradients provide a useful insight into modeling of species' responses expected under future climate change (Kooyers et al. 2014). Transplantation experiments between high and low altitudes have been extensively used to test for the direct effects of temperature on plants and ecosystems (Walker et al. 2018). The altitudinal gradients of montane forests provide an opportunity to establish the relationships between tree species and multiple environmental factors (Salinas et al. 2011).

Zhou et al. (2011) demonstrated that the annual temperature in subtropical China has increased by approximately $1.0{ }^{\circ} \mathrm{C}$ in the past five decades. Hence, we conducted a downward transplantation experiment to investigate the effects of warming on tree growth and several functional traits. Saplings and soils from $600 \mathrm{~m}$ were transplanted to $300 \mathrm{~m}$ and $30 \mathrm{~m}$ to induce an effective warming of $1.0{ }^{\circ} \mathrm{C}$ and $1.5{ }^{\circ} \mathrm{C}$. We selected Schima superba Gardn. et Champ., Syzygium rehderianum Merr. et Perry, Itea chinensis Hook. et Arn., and Machilus breviflora (Benth.) Hemsl., four naturally co-occurring tree species that inhabit subtropical montane forests in southern China. We addressed the following questions: (Anadon-Rosell et al. 2018) how does climatic warming affect growth of co-occurring tree species in the subtropical montane forest of southern China and (Aspinwall et al. 2016) what physiological and morphological processes are involved in the growth responses of these tree species to climate warming?

\section{Materials and methods}

\subsection{Study site}

Our study was conducted at the Dinghushan Biosphere Reserve, a UNESCO/MAB site located in central Guangdong Province in southern China $\left(112^{\circ} 10^{\prime} \mathrm{E}\right.$, $\left.23^{\circ} 10^{\prime} \mathrm{N}\right)$. This region has a typical subtropical monsoon climate, with annual precipitation of $1956 \mathrm{~mm}$ and annual mean air temperature of $21{ }^{\circ} \mathrm{C}$ (Zhou et al. 2014). The bedrock is sandstone and shale. Soils are classified as ultisols with a $\mathrm{pH} 4.0-4.9$ in the top $5 \mathrm{~cm}$ (Zhou et al. 2011).

\subsection{Transplantation and monitoring}

We conducted a transplantation experiment in three field sites along an altitudinal gradient. A high-elevation site (600 $\mathrm{m}$ a.s.1) served as control to assess the effect of 
transplantation to a middle-elevation (300 $\mathrm{m}$ a.s.l) and a low-elevation site $(30 \mathrm{~m}$ a.s.l). At each site, three blocks ( $3.0 \mathrm{~m}$ in length and width, $0.8 \mathrm{~m}$ in depth) were established in an open area and were exposed to natural sunlight and rainfall.

In April 2012, soil and 1-year-old seedlings were collected from a montane evergreen broadleaved forest close to the $600 \mathrm{~m}$ site. Three different layers of soils $(0-20,20-40$, and 40-70 cm) were homogenized separately. Seedlings were stored in shade containers with soil from the collection forest. In May 2012, three different layers of soils were transferred into each block correspondingly. Seedlings were transplanted into each block in a randomized block design ( $n=6$ replicates per species). The four species included in this study were specifically selected due to their common occurrence and distribution range (existence in almost all regions along the altitudinal gradient) from the montane forest. They included Schima superba Gardn. et Champ., Syzygium rehderianum Merr. et Perry., Machilus breviflora (Benth.) Hemsl., and Itea chinensis Hook. et Arn.

From May 2013, air temperature, soil temperature, and volumetric soil water content at each block were continuously recorded and recently been published (Liu et al. 2017; $\mathrm{Wu}$ et al. 2019). The average air temperature at the altitude of $300 \mathrm{~m}$ and $30 \mathrm{~m}$ were $1.0{ }^{\circ} \mathrm{C}$ and $1.5^{\circ} \mathrm{C}$ higher to the altitude of $600 \mathrm{~m}$, respectively (Wu et al. 2019). The monthly mean volumetric soil water content was $0.18,0.20$, and $0.16 \mathrm{~m}^{3} \mathrm{~m}^{-3}$ at $600 \mathrm{~m}, 300 \mathrm{~m}$, and $30 \mathrm{~m}$, respectively (Wu et al. 2019).

\section{3 $\mathrm{D}^{2} \mathrm{H}$, leaf area, and photosynthesis measurements}

In June 2014 and 2015, tree heights $(\mathrm{H})$ and basal diameters (D) of each tree in each block were measured to calculate $\mathrm{D}^{2} \mathrm{H}$. For specific leaf area (SLA), five fully expanded sunexposed leaves were collected from three individuals per species in each block. Total areas of sampled leaves were determined by a portable leaf area meter (Li-3100A, Li-Cor, USA). The leaves were then oven dried for $72 \mathrm{~h}$ at $70^{\circ} \mathrm{C}$ to determine dry weight. SLA was calculated as the ratio of leaf area to dry mass.

Leaf gas exchange was measured on newly developed and fully expanded leaves from three individuals per species in each block using a portable open path gas exchange system (Li-6400XT, Li-Cor, USA) supplying photosynthetic photon flux (PPFD) by red-blue light source (6400-02B). Light-saturated photosynthesis was measured at midday (between 0930 and $1300 \mathrm{~h}$ ) on a monthly basis throughout the experiment, at PPFD of $1500 \mu \mathrm{mol} \mathrm{m}^{-2} \mathrm{~s}^{-1}$ and $\left[\mathrm{CO}_{2}\right]$ of $400 \mu \mathrm{mol} \mathrm{mol}^{-1}$. Temperature and relative humidity in Licor-6400XT cuvettes were maintained at the initial air values throughout the measurements, representing the environmental conditions in the block during the day.

\subsection{Non-structural carbohydrate (soluble sugar and starch)}

To determine soluble sugar and starch concentration, one seedling per species from each block was randomly selected for destructive harvest on December 2014. Seedlings were separated into leaves, stem, and roots. Oven-dried plant organ samples were ground to fine powder in a ball mill. Soluble sugars were extracted using an ethanol technique and determined using the anthrone colorimetric assay (Ebell 1969). Starch was determined enzymatically using a total starch assay kit (Megazyme International Ireland Ltd., Wicklow, Ireland). Non-structural carbohydrate concentration was calculated as the sum of soluble sugar and starch concentrations.

\subsection{Stomatal length and stomatal density}

In June 2014, four leaves from three individuals per species were collected in each block. Leaf epidermises on the adaxial side were taken centrally in the leaf midway. The epidermises were mounted on a microscope slide and observed using a light microscope (DM2500, Leica, Germany). For each epidermal peel, 20 stomata were sampled to measure length and three fields $\left(0.16 \mathrm{~mm}^{2}\right)$ were sampled for density.

\subsection{Statistical analysis}

All analyses were conducted using SPSS 17.0 (SPSS Inc., Illinois, USA). We chose $\alpha$ equal to 0.05 . Data normality and residual homogeneity were checked prior to analysis. Repeated-measures ANOVA were conducted to examine the main and interactive effects of transplantation, species, measuring (or sampling) time on light-saturated photosynthetic rate, stomatal conductance, $\mathrm{D}^{2} \mathrm{H}$, and specific leaf area. In addition, the transplantation effect and its interaction with species on stomatal length, density, and NSCs were analyzed by two-way ANOVA. When the effects were significant, they were further analyzed using Tukey multiple comparison test (honestly significant difference). Relationships between lightsaturated photosynthetic rate, leaf temperature, and stomatal conductance at each site were analyzed using non-linear and linear regression analysis, respectively.

\section{Results}

\section{1 $\mathrm{D}^{2} \mathrm{H}$ and specific leaf area}

Transplantation and species significantly affected specific leaf area (SLA) and $\mathrm{D}^{2} \mathrm{H}(p<0.01$, Table 1). Transplantation from 600 to $300 \mathrm{~m}$ significantly increased $\mathrm{D}^{2} \mathrm{H}$ of $I$. chinensis, with no significant effect on other species. Transplantation from 600 to $30 \mathrm{~m}$ significantly increased $\mathrm{D}^{2} \mathrm{H}$ of $S$. superba, 
Table 1 Results from repeatedmeasures ANOVA analysis for the effects of measuring (sampling) time, transplantation (T), species and their interactions on $\mathrm{D}^{2} \mathrm{H}$, specific leaf area, saturating light photosynthetic rate, and stomatal conductance

\begin{tabular}{lllllllll}
\hline Source variation & $\mathrm{D}^{2} \mathrm{H}$ & $\mathrm{Dfs}$ & $\begin{array}{l}\text { Specific } \\
\text { leaf area }\end{array}$ & $\begin{array}{l}\text { Dfs } \\
\text { Photosynthetic } \\
\text { rate }\end{array}$ & Dfs & $\begin{array}{l}\text { Stomatal } \\
\text { conductance }\end{array}$ & Dfs \\
\hline Time & $320.88^{* * *}$ & 1 & $130.19 * * *$ & 1 & $117.46^{* * * *}$ & 9 & $177.68 * * *$ & 9 \\
$\mathrm{~T}$ & $33.66 * * *$ & 2 & $10.54 * *$ & 2 & $135.02 * * *$ & 2 & $75.72 * * *$ & 2 \\
Time $\times \mathrm{T}$ & $20.24 * * *$ & 2 & $13.39 * * *$ & 2 & $3.28 * * *$ & 18 & $11.22 * * *$ & 18 \\
Species & $37.50 * * *$ & 3 & $25.72 * * *$ & 3 & $423.38 * * *$ & 3 & $70.89 * * *$ & 3 \\
Time $\times$ species & $26.95 * * *$ & 3 & 2.50 & 3 & $9.03 * * *$ & 27 & $9.92 * * *$ & 27 \\
$\mathrm{~T} \times$ Species & $7.72 * * *$ & 6 & 0.36 & 6 & $5.39 * * *$ & 6 & $2.88^{*}$ & 6 \\
Time $\times \mathrm{T} \times$ species & $5.04 * *$ & 6 & 0.81 & 6 & 1.06 & 54 & $2.59 * *$ & 54 \\
\hline
\end{tabular}

Numbers and Dfs are F-values and their degrees of freedom, respectively. No asterisk $=$ not significant Asterisks indicate the level of significance; $* p<0.05 ; * * p<0.01 ; * * p<0.001$
$S$. rehderianum and $I$. chinensis, with no significant effect on M. breviflora (Fig. 1).

Transplantation from 600 to $300 \mathrm{~m}$ significantly increased SLA of S. superba, M. breviflora, and I. chinensis in 2015 ( $p<0.05$, Fig. 1), but had no effect in 2014 . No obvious difference was detected in SLA of all species between the altitudes of 30 and $600 \mathrm{~m}$ in 2014 and 2015.

\subsection{Light-saturated photosynthesis}

Light-saturated photosynthetic rate of the four measured species in each site fluctuated along the experimental period. Interactive effects of transplantation and species on photosynthetic rate were detected (Table 1). Transplantation from $600 \mathrm{~m}$ (mean leaf temperature of $25.8{ }^{\circ} \mathrm{C}$ during
Fig. 1 Effects of transplantation on $\mathrm{D}^{2} \mathrm{H}(\mathbf{a}, \mathbf{b})$ and specific leaf area $(\mathbf{c}, \mathbf{d})$ of the four studies species grown at three altitudes in June 2014 (left panels) and June 2015 (right panels). Bars with different lowercase letters indicate significant differences among three altitudes in each species according to Turkey multiple comparison test $(\alpha=0.05)$. Mean values $( \pm \mathrm{SE})$ are those of replicate blocks $(n=$ 3 ), determined based on three individual measures per block
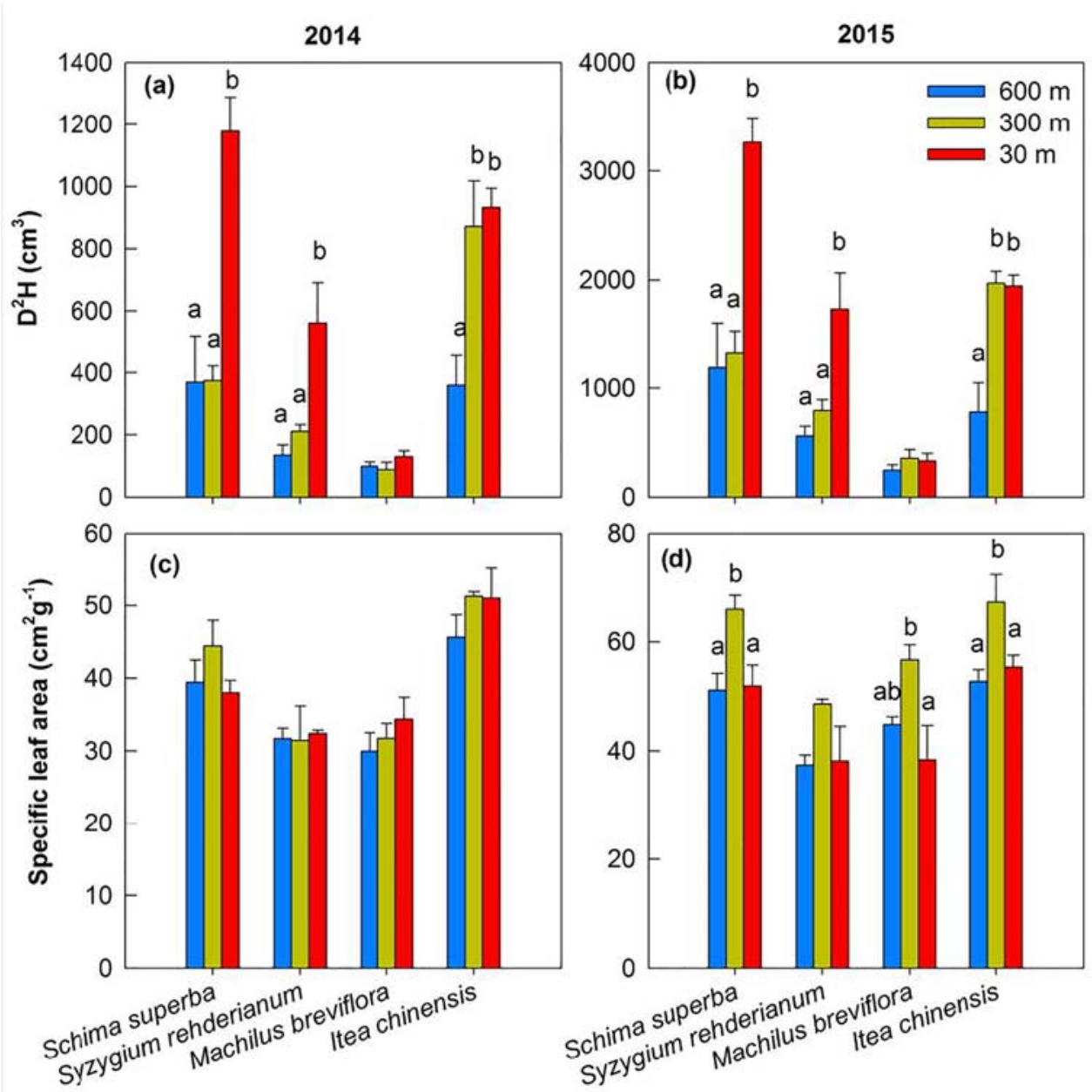
measurements) to $300 \mathrm{~m}$ (mean leaf temperature of $27.2^{\circ} \mathrm{C}$ during measurements) significantly increased photosynthetic rate of $S$. rehderianum $(p<0.01)$ and $M$. breviflora $(p<0.05)$ but had no effect on $S$. superba and $I$. chinensis (Fig. 2). Transplantation from 600 to $30 \mathrm{~m}$ (mean leaf temperature of $28.7^{\circ} \mathrm{C}$ during measurements) significantly increased light-saturated photosynthetic rate and stomatal conductance of $S$. superba, S. rehderianum, M. breviflora and $I$. chinensis ( $p<0.01$ for all species, Fig. 2). Lightsaturated photosynthetic rates were positively correlated with leaf temperatures and stomatal conductance for $S$. superba, S. rehderianum, $M$. breviflora, and I. chinensis $(p<0.05$ for all species, Figs. 3 and 4$)$. The regressions separated clearly between three sites for all four species.

\subsection{Stomatal length and density}

In general, transplantation had no significant effect on stomatal length and density (Table 1), with no interaction with species. There was no difference between the stomatal length and density of all tree species at the altitude of $300 \mathrm{~m}$ and $30 \mathrm{~m}$. Transplantation only decreased the stomatal density of $M$. breviflora from 600 to $30 \mathrm{~m}(p<0.05$, Fig. 5).

\subsection{Non-structural carbohydrates}

Soluble sugar, starch, and non-structural carbohydrate content varied significantly between species and organs and were all affected significantly by transplantation (Tables 1 and 2). Transplantation significantly increased concentrations of non-structural carbohydrates in leaves of $S$. rehderianum and $M$. breviflora, stems of $S$. superba and $S$. rehderianum, and roots of I. chinensis (Table 3).

\section{Discussion}

In this study, we found that temperatures of $1-1.5^{\circ} \mathrm{C}$ above the control increased $\mathrm{D}^{2} \mathrm{H}$ in saplings of $S$. superba, $S$. rehderianum, and I. chinensis grown at warmer temperatures. These results did not support the widely assumed hypothesis that climate warming would have negative effect on subtropical tree growth (Clark et al. 2010). Several observational studies concerning canopy trees indicated negative correlations between growth and temperature in tropical forests (Clark et al. 2014). Some sapling studies suggest the opposite results (Cheesman and Klaus 2013; Fahey et al. 2016; Slot and Winter 2018). Consistent with positive effects on growth, we also found increased light-saturated photosynthetic rates for
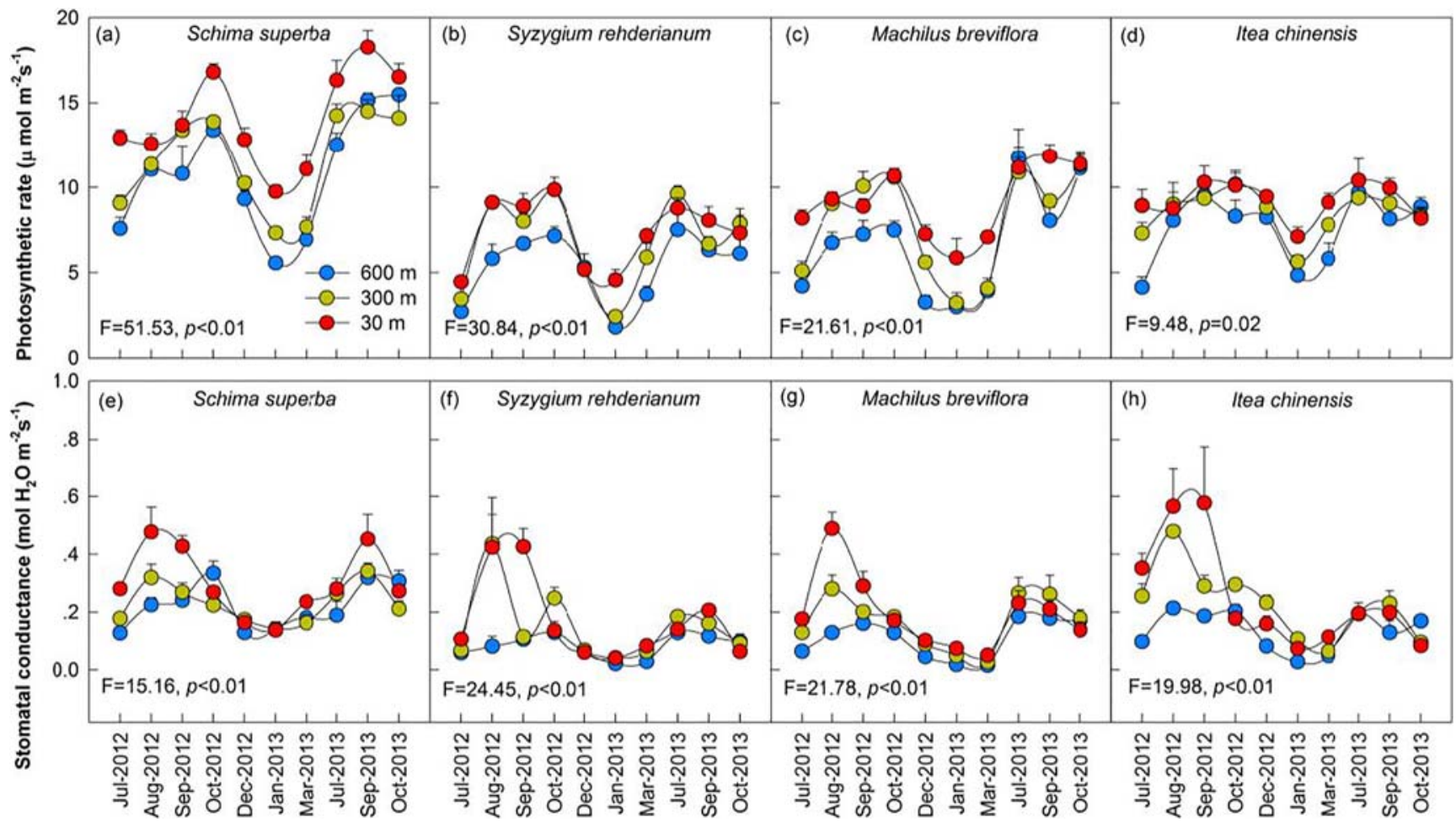

Fig. 2 Effects of transplantation on light-saturated photosynthetic rate and stomatal conductance of the four studies species grown at three altitudes from July 2012 to October 2013. Mean values ( \pm SE) are those of

replicate blocks $(n=3)$, determined based on three individual leaf measures per block. Repeated-measures ANOVA results (F and $P$ values) of transplantation are shown 
Fig. 3 Regression analysis of light-saturated photosynthetic rate with leaf temperature for the four studies species grown at three altitudes. Values are single records. Data are fitted with a quadratic equation and only significant relationships are showed

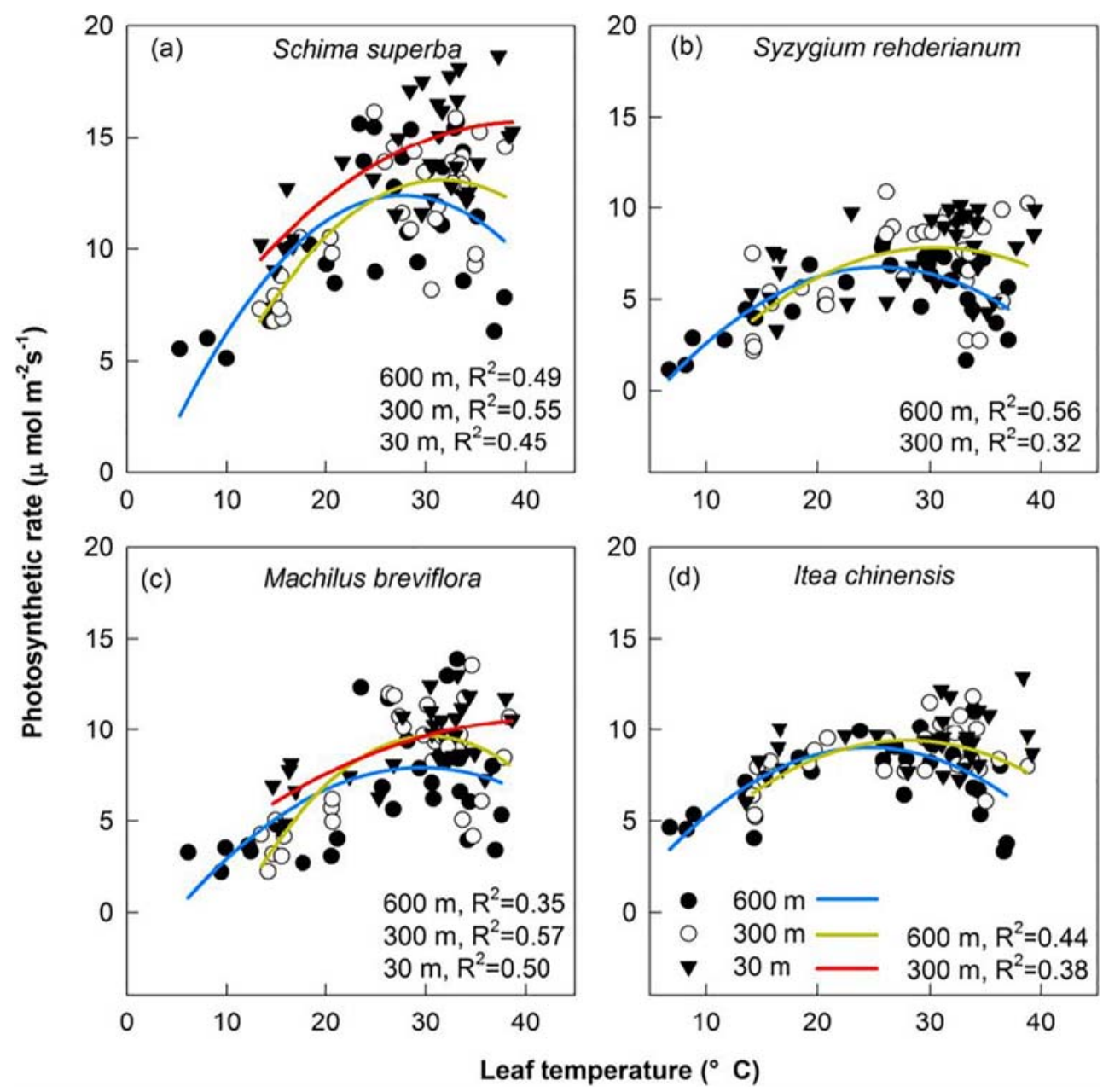

all four tree species grown in lower altitudes during both wet and dry seasons (Table 2; Fig. 2). Enhancements in photosynthetic rate in response to transplantation were largely associated with changes in stomatal conductance (Fig. 4). Previous studies found that stomatal conductance is negatively correlated with vapor pressure deficit (VPD), which often exhibit declines under warming because air relative humidity increases to a greater extent than temperature (Duursma et al. 2014). Therefore, in our study, increased temperature and lower VPD can lead to increased stomatal conductance and thus to photosynthetic rate.

It is clear from the relationships between light-saturated photosynthetic rates and seasonal temperature variation at prevailing temperatures that the optimum temperature for the saplings growing at lower altitudes seems to be higher than that at high altitude. In general, light-saturated photosynthetic rates had already commenced to decline at temperatures above $28-31^{\circ} \mathrm{C}$. This result indicated that climate warming will have negative impacts on photosynthesis of these saplings during the warm period of the year. In addition, photosynthesis exhibited at least partial thermal acclimation, which varied with species and altitudes, either from the seasonal variations
(Fig. 2) or from leaf temperature-response curves (Fig. 3). This could be a predominant cause of the altitudinal shift in optimum temperature. Unfortunately, we cannot directly quantify the effects of acclimation on this result because we did not measure gas exchange at a set constant measurement leaf temperature (corresponding value were $25.8^{\circ} \mathrm{C}, 27.2^{\circ} \mathrm{C}$, $28.7^{\circ} \mathrm{C}$ in average for $600 \mathrm{~m}, 300 \mathrm{~m}$, and $30 \mathrm{~m}$, respectively, in this study). Clearly, more detailed temperature-response measurements in natural environments, which are quite limited, will be needed to focus on the capacity for thermal acclimation of photosynthesis and its consequences in tropical species.

Several morphological adjustments may have helped ensure plant acclimate to elevated temperature. When exposed to favorable environments (e.g., warm and wet), plants tend to produce higher specific leaf area (SLA) (Yuan et al. 2018), which is positively related to light-saturated photosynthetic rate and growth rate (Perez-Harguindeguy et al. 2013). In addition, there is a clear difference in the response of boreal and tropical species, with the tropical species changing SLA more for a given change in temperature (Poorter et al. 2009). In our study, SLA showed substantial phenotypic plasticity 
Fig. 4 Regression analysis of light-saturated photosynthetic rate with stomatal conductance for the four studied species grown at three altitudes. Values are single records. Data are fitted with a linear equation and only significant relationships are showed
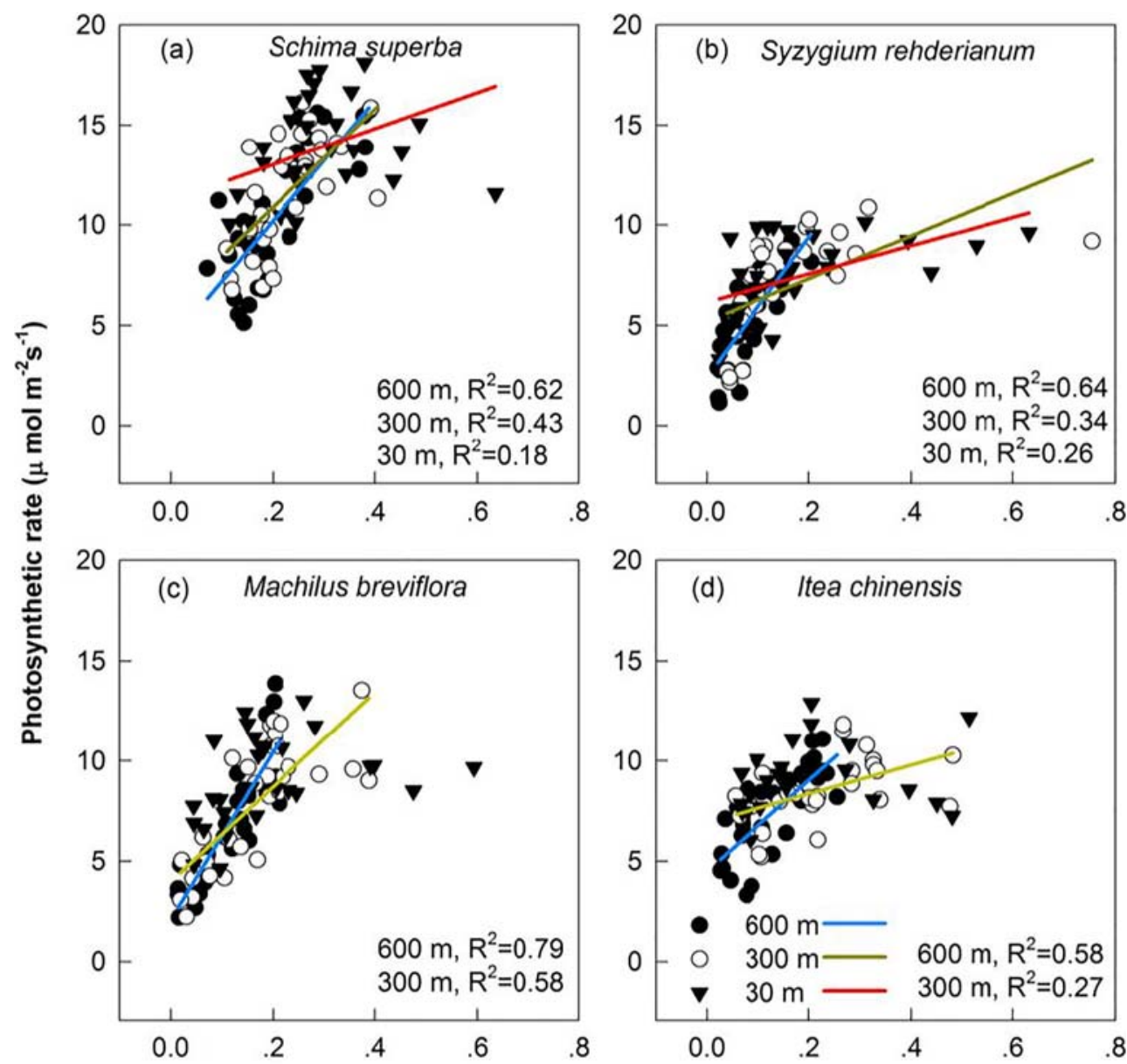

Stomatal conductance $\left(\mathrm{mol} \mathrm{H}_{2} \mathrm{O} \mathrm{m}^{-2} \mathrm{~s}^{-1}\right.$ )

after 3 years, as indicated by a significant increase in SLA of S. superba and I. chinensis with transplantation from 600 to $300 \mathrm{~m}$, in accordance with previous studies (Hamann et al. 2018; Barbosa et al. 2018). The increase in SLA with downward transplantation can be achieved through decreases in leaf density and/or leaf thickness, leading to greater efficiency in light capture (Gratani 2014). In addition to altered SLA, higher photosynthetic rate under warming might be associated with warming-induced changes in stomatal density and length, which are the two primary morphological regulators
Fig. 5 Effects of transplantation on stomatal length (a) and density (b) of the four studied species grown at three altitudes in June 2014. Bars with different lowercase letters indicate significant differences among three altitudes in each species according to Turkey multiple comparison test $(\alpha=0.05)$. Mean values $( \pm \mathrm{SE})$ are those of replicate blocks $(n=3)$, determined based on three individual leaf measures per block

Table 2 Results from two-way ANOVA analysis for the effects of transplantation, species, and their interactions on stomatal length, density, soluble sugar (ss), starch (st), and non-structural carbohydrate content (NSCs)

\begin{tabular}{lllllll}
\hline Variables & Transplantation & Dfs & Species & Dfs & Transplantation $\times$ species & Dfs \\
\hline Stomatal length & 1.12 & 2 & $31.12^{* * * *}$ & 3 & 0.38 & 6 \\
Stomatal density & 0.06 & 2 & $75.99^{* * *}$ & 3 & 0.48 & 6 \\
Leaf ss & $16.08^{* * *}$ & 2 & $26.55^{* * *}$ & 3 & $4.82^{* * *}$ & 6 \\
Leaf st & $11.65^{* * *}$ & 2 & 1.64 & 3 & $6.98^{* * *}$ & 6 \\
Leaf NSCs & $14.23^{* * *}$ & 2 & $12.62^{* * *}$ & 3 & $3.81^{* * *}$ & 6 \\
Stem ss & $17.50^{* * *}$ & 2 & $24.40^{* * *}$ & 3 & $3.07 *$ & 6 \\
Stem st & 1.75 & 2 & 2.88 & 3 & 1.52 & 6 \\
Stem NSCs & 1.61 & 2 & $7.43^{* *}$ & 3 & 1.75 & 6 \\
Root ss & $4.76^{*}$ & 2 & $28.49^{* * * *}$ & 3 & 1.89 & 6 \\
Root st & 0.54 & 2 & $22.35^{* * *}$ & 3 & $4.25 * *$ & 6 \\
Root NSCs & 0.95 & 2 & $44.32^{* * * *}$ & 3 & $3.81^{* *}$ & 6 \\
\hline
\end{tabular}

Numbers and Dfs are F-values and their degrees of freedom, respectively. No asterisk $=$ not significant Asterisks indicate the level of significance; $* p<0.05 ; * * p<0.01 ; * * * p<0.001$ controlling the response of stomatal conductance to climatic stresses (Franks et al. 2015). Some earlier studies have shown that stomata traits of trees can vary with changing temperature (Wu et al. 2018). However, in our study, only transplantation from 600 to $30 \mathrm{~m}$ decreased the stomatal density of M. breviflora (Fig. 5). In general, lower stomatal density would prevent excessive plant water use, as a potential tool for enhancing drought tolerance without significantly affecting photosynthetic capacity (Franks et al. 2015; Hepworth et al. 2015).

Non-structural carbohydrates (NSCs, sum of soluble sugar and starch) stores play a functional role for plant metabolism under stress (Dietze et al. 2014). Several studies found that warming may increase (Djanaguiraman et al. 2011; Zheng et al. 2018), decrease (Tang et al. 2016), or have little effect (Marias et al. 2016) on the concentration of NSCs in plants. In the present study, warming induced an increase of NSCs in leaves of $S$. rehderianum and $M$. breviflora, stems of $S$. superba and $S$. rehderianum, roots of I. chinensis, and concurrent with a decrease of NSCs in roots of $M$. breviflora. Our results also indicated an increase in soluble sugar and a decrease in starch. This may indicate new production of soluble sugar with concurrent consumption of starch or the hydrolyzation of starch to soluble sugar in response to warming (Kozlowski 1992), which allows the maintenance of water absorption and cell turgor under water deficits. Marias et al. (2016) also found that warming induced significant increase of soluble sugars accompanied by a reduction of starch in leaves of Pinus ponderosa and Pseudotsuga menziesii.

In this study, the distinct responses of growth and functional traits to elevated temperature among the four tree species revealed different adaptive strategies under climate warming. $S$. superba is a representative dominant species in subtropical and tropical forest in China, valued commercially for its timber and can also prevent the spread of fire. In this study, it had the highest photosynthetic rate of all species, regardless of transplantation, and also showed greatest enhancement in photosynthetic rate and growth with warming of all species. M. breviflora, which is a shade-tolerant species that distributed in southern subtropical and tropical forests, was the only species showing no change in growth with transplantation. In this study, it is apparent that elevated temperatures can markedly stimulate growth of $S$. superba, S. rehderianum, and I. chinensis at the sapling stage. Currently, we are not sure the degree to which our results, obtained from saplings of four species, can be extended to mature trees. Gunderson et al. (2010) made direct comparisons of acclimation potential for seedling-sapling size trees and those of mature trees under experimental warming. They found that photosynthesis acclimation occurred regardless of tree age and size. If our results can similarly translate to mature trees, this could result in shifts of species composition and community structure in subtropical forests, with long-term climatic consequences. Ideally, further experiments using mature trees from a wide variety of species, which is expensive and challenging, would need to be carried out to ascertain the response of mature trees to climate warming. The results from younger trees, as in this study, offer a valuable insight into the potential effects on a wider range of tree species.

\section{Conclusion}

We investigated how transplantation-induced warming affected morphological and physiological performance of four subtropical co-occurring tree species. Although relatively high temperature already exist in subtropical areas, we found positive effect on growth of $S$. superba, $S$. rehderianum, and I. chinensis, accompanied by increased photosynthetic rate and specific leaf area. Stimulations of photosynthesis in 





response to warming conditions were associated with those in leaf temperature and stomatal conductance. Warming also significantly increased concentrations of NSCs in leaves of $S$. rehderianum and $M$. breviflora, stems of $S$. superba and $S$. rehderianum, and roots of $I$. chinensis. Our results highlight that subtropical tree species have species-specific capacities to acclimate to elevated temperature that will likely occur in the coming decades under climate change, and ultimately improve our understanding of performances in the adaptive potential of tropical saplings. Results from our sapling study may not be directly extrapolated to adult studies. However, our study offers a valuable insight into the potential effects on a wider range of tree species. Further studies need to be conducted on mature trees to obtain more information in tropical forest responses to future climates.

Acknowledgments We thank the editor and the two anonymous reviewers for valuable comments.

Data availability statement The datasets generated during and/or analyzed during the current study are not publicly available because the authors are working on another manuscript using the same dataset but are available from the corresponding author on reasonable request.

Funding information This study was jointly funded by the National Natural Science Foundation of China (31800511, 31570482 and 31670453), the Science and Technology Innovation Project of Guangdong Province Forestry (Grant No. 2019KJCX023), and the Fund of Key Laboratory of Vegetation Restoration and Management of Degraded Ecosystems, Chinese Academy of Sciences (DE2018028).

\section{Compliance with ethical standards}

Statement on ethical approval We declare that this study have obtained the appropriate permissions from the responsible authorities of "Dinghushan Biosphere Reserve."

Conflict of interest The authors declare that they have no conflict of interest.

\section{References}

Anadon-Rosell A, Dawes MA, Fonti P, Hagedorn F, Rixen C, von Arx G (2018) Xylem anatomical and growth responses of the dwarf shrub Vaccinium myrtillus to experimental $\mathrm{CO}_{2}$ enrichment and soil warming at treeline. Sci Total Environ 642:1172-1183

Aspinwall MJ, Drake JE, Campany C, Vårhammar A, Ghannoum O, Tissue DT, Reich PB, Tjoelker MG (2016) Convergent acclimation of leaf photosynthesis and respiration to prevailing ambient temperatures under current and warmer climates in Eucalyptus tereticornis. New Phytol 212:354-367

Barbosa C, Pugnaire FI, Peroni N, Castellani TT (2018) Warming effects on the colonization of a coastal ecosystem by Furcraea foetida (Asparagaceae), a clonal invasive species. Plant Ecol 219:813-821

Burke M, Hsiang SM, Miguel E (2015) Global non-linear effect of temperature on economic production. Nature 527:235-239
Cheesman AW, Klaus W (2013) Elevated night-time temperatures increase growth in seedlings of two tropical pioneer tree species. New Phytol 197:1185-1192

Clark DB, Clark DA, Oberbauer SF (2010) Annual wood production in a tropical rain forest in NE Costa Rica linked to climatic variation but not to increasing $\mathrm{CO}_{2}$. Glob Chang Biol 16:747-759

Clark DA, Clark DB, Oberbauer SF (2014) Field-quantified response of tropical rainforest aboveground productivity to increasing $\mathrm{CO}_{2}$ and climatic stress, 1997-2009. J Geophys Res-Biogeo 118:783-794

Dietze MC, Sala A, Carbone MS, Czimczik CI, Mantooth JA, Richardson AD, Vargas R (2014) Nonstructural carbon in woody plants. Annu Rev Plant Biol 65:667-687

Djanaguiraman M, Prasad PVV, Boyle DL, Schapaugh WT (2011) Hightemperature stress and soybean leaves: leaf anatomy and photosynthesis. Crop Sci 51:2125-2131

Drake JE, Aspinwall MJ, Pfautsch S, Rymer PD, Reich PB, Smith RA, Crous KY, Tissue DT, Ghannoum O, Tjoelker MG (2015) The capacity to cope with climate warming declines from temperate to tropical latitudes in two widely distributed Eucalyptus species. Glob Chang Biol 21:459-472

Duursma R, Barton C, Lin Y, Medlyn B, Eamus D, Tissue D, Ellsworth D, McMurtrie R (2014) The peaked response of transpiration rate to vapour pressure deficit in field conditions can be explained by the temperature optimum of photosynthesis. Agric For Meteorol 189:2 10

Ebell L (1969) Variation in total soluble sugars of conifer tissues with method of analysis. Phytochemistry 8:227-233

Fahey C, Winter K, Slot M, Kitajima K (2016) Influence of arbuscular mycorrhizal colonization on whole-plant respiration and thermal acclimation of tropical tree seedlings. Ecol Evol 6:859-870

Franks PJ, Doheny-Adams TW, Britton-Harper ZJ, Gray JE (2015) Increasing water-use efficiency directly through genetic manipulation of stomatal density. New Phytol 207:188-195

Gratani L (2014) Plant phenotypic plasticity in response to environmental factors. Adv Bot 2014:17

Gunderson CA, O'hara KH, Campion CM, Walker AV, Edwards NT (2010) Thermal plasticity of photosynthesis: the role of acclimation in forest responses to a warming climate. Glob Chang Biol 16:22722286

Hamann E, Kesselring H, Stöcklin J (2018) Plant responses to simulated warming and drought: a comparative study of functional plasticity between congeneric mid and high elevation species. J Plant Ecol 11: 364-374

Hartmann H, Trumbore S (2016) Understanding the roles of nonstructural carbohydrates in forest trees-from what we can measure to what we want to know. New Phytol 211:386-403

Hepworth C, Doheny-Adams T, Hunt L, Cameron DD, Gray JE (2015) Manipulating stomatal density enhances drought tolerance without deleterious effect on nutrient uptake. New Phytol 208:336-341

IPCC (2014) Summary for policymakers. In: Field CB, Barros VR, Mastrandrea MD, Mach KJ, MAK A, Adger N, Anokhin YA, Anisimov OA, Arent DJ, Barnett J, Burkett V, Cai R (eds) Climate Change 2014: Impacts, Adaptation, and Vulnerability. Part A: Global and Sectoral Aspects. Contribution of Working Group II to the Fifth Assessment Report of the Intergovernmental Panel on Climate Change. Cambridge University Press, Cambridge and NY pp 1-32

Jump AS, Hunt JM, Penuelas J (2006) Rapid climate change-related growth decline at the southern range edge of Fagus sylvatica. Glob Chang Biol 12:2163-2174

Kooyers NJ, Greenlee AB, Colicchio JM, Oh M, Blackman BK (2014) Replicate altitudinal clines reveal that evolutionary flexibility underlies adaptation to drought stress in annual Mimulus guttatus. New Phytol 206:152-165

Kozlowski TT (1992) Carbohydrate sources and sinks in woody plants. Bot Rev 58:107-222 
Liu J, Liu S, Li Y, Liu S, Yin G, Huang J, Xu Y, Zhou G (2017) Warming effects on the decomposition of two litter species in model subtropical forests. Plant Soil 420:277-287

Marias DE, Meinzer FC, Woodruff DR, Mcculloh KA (2016) Thermotolerance and heat stress responses of Douglas-fir and ponderosa pine seedling populations from contrasting climates. Tree Physiol 37:301-315

Peñuelas J, Ogaya R, Boada M, Jump AS (2007) Migration, invasion and decline: changes in recruitment and forest structure in a warminglinked shift of European beech forest in Catalonia (NE Spain). Ecography 30:829-837

Perez-Harguindeguy N, Diaz S, Garnier E, Lavorel S, Poorter H, Jaureguiberry P et al (2013) New handbook for standardised measurement of plant functional traits worldwide. Aust J Bot 61:167234

Poorter H, Niinemets Ü, Poorter L, Wright IJ, Villar R (2009) Causes and consequences of variation in leaf mass per area (LMA): a metaanalysis. New Phytol 182:565-588

Prieto P, Peñuelas J, Llusià J, Asensio D, Estiarte M (2009) Effects of long-term experimental night-time warming and drought on photosynthesis, Fv/Fm and stomatal conductance in the dominant species of a Mediterranean shrubland. Acta Physiol Plant 31:729-739

Rodgers VL, Smith NG, Hoeppner SS, Dukes JS (2018) Warming increases the sensitivity of seedling growth capacity to rainfall in six temperate deciduous tree species. Aob Plants 10(1):ply003. https:// doi.org/10.1093/aobpla/ply003

Salinas N, Malhi Y, Meir P, Silman M, Roman Cuesta R, Huaman J, Salinas D, Huaman V, Gibaja A, Mamani M, Farfan F (2011) The sensitivity of tropical leaf litter decomposition to temperature: results from a large-scale leaf translocation experiment along an elevation gradient in Peruvian forests. New Phytol 189:967-977

Salvucci ME, Crafts-Brandner SJ (2004) Inhibition of photosynthesis by heat stress: the activation state of Rubisco as a limiting factor in photosynthesis. Physiol Plant 120:179-186

Sheldon KS, Yang S, Tewksbury JJ (2011) Climate change and community disassembly: impacts of warming on tropical and temperate montane community structure. Ecol Lett 14:1191-1200

Slot M, Winter K (2017) Photosynthetic acclimation to warming in tropical forest tree seedlings. J Exp Bot 68:2275-2284

Slot M, Winter K (2018) High tolerance of tropical sapling growth and gas exchange to moderate warming. Funct Ecol 32:599-611

Tang B, Yin C, Wang Y, Sun Y, Liu Q (2016) Positive effects of night warming on physiology of coniferous trees in late growing season: leaf and root. Acta Oecol-Int J Ecol 73:21-30

Thomas CD, Cameron A, Green RE, Bakkenes M, Beaumont LJ, Collingham YC, Erasmus BF, de Siqueira MF, Grainger A, Hannah L, Hughes L, Huntley B, van Jaarsveld A, Midgley GF, Miles L, Ortega-Huerta MA, Peterson AT, Phillips OL, Williams SE (2004) Extinction risk from climate change. Nature 427:145-148

Trahan MW, Schubert BA (2016) Temperature-induced water stress in high-latitude forests in response to natural and anthropogenic warming. Glob Chang Biol 22:782-791

Walker TWN, Weckwerth W, Bragazza L, Fragner L, Forde BG, Ostle NJ, Signarbieux C, Sun X, Ward SE, Bardgett RD (2018) Plastic and genetic responses of a common sedge to warming have contrasting effects on carbon cycle processes. Ecol Lett 22:159-169

Wang J, Duan B, Zhang Y (2012) Effects of experimental warming on growth, biomass allocation, and needle chemistry of Abies faxoniana in even-aged monospecific stands. Plant Ecol 213:47-55

Way DA, Oren R (2010) Differential responses to changes in growth temperature between trees from different functional groups and biomes: a review and synthesis of data. Tree Physiol 30:669-688

Way DA, Oren R, Kroner Y (2015) The space-time continuum: the effects of elevated $\mathrm{CO}_{2}$ and temperature on trees and the importance of scaling. Plant Cell Environ 38:991-1007

Wertin TM, McGuire MA, Teskey RO (2011) Higher growth temperatures decreased net carbon assimilation and biomass accumulation of northern red oak seedlings near the southern limit of the species range. Tree Physiol 31:1277-1288

Wu G, Liu H, Hua L, Luo Q, Lin Y, He P, Feng S, Liu J, Ye Q (2018) Differential responses of stomata and photosynthesis to elevated temperature in two co-occurring subtropical forest tree species. Front Plant Sci 9:467. https://doi.org/10.3389/fpls.2018.00467

Wu T, Qu C, Li Y, Li X, Zhou G, Liu S, Chu G, Meng Z, Lie Z, Liu J (2019) Warming effects on leaf nutrients and plant growth in tropical forests. Plant Ecol 220:663-674

Xu C-Y, Salih A, Ghannoum O, Tissue DT (2012) Leaf structural characteristics are less important than leaf chemical properties in determining the response of leaf mass per area and photosynthesis of Eucalyptus saligna to industrial-age changes in $\left[\mathrm{CO}_{2}\right]$ and temperature. J Exp Bot 63:5829-5841

$\mathrm{Xu}$ Z, Jiang Y, Jia B, Zhou G (2016) Elevated- $\mathrm{CO}_{2}$ response of stomata and its dependence on environmental factors. Front Plant Sci 7:657. https://doi.org/10.3389/fpls.2016.00657

Yuan Y, Ge L, Yang H, Ren W (2018) A meta-analysis of experimental warming effects on woody plant growth and photosynthesis in forests. J For Res 29:727-733

Zheng Y, Guo L, Hou R, Zhou H, Hao L, Li F, Cheng D, Peng Z, Xu M (2018) Experimental warming enhances the carbon gain but does not affect the yield of maize (Zea mays L.) in the North China plain. Flora 240:152-163

Zhou G, Wei X, Wu Y, Liu S, Huang Y, Yan J, Zhang D, Zhang Q, Liu J, Meng Z, Wang C, Chu G, Liu S, Tang X, Liu X (2011) Quantifying the hydrological responses to climate change in an intact forested small watershed in southern China. Glob Chang Biol 17:3736-3746

Zhou G, Peng C, Li Y, Liu S, Zhang Q, Tang X, Liu J, Yan J, Zhang D, Chu G (2013) A climate change-induced threat to the ecological resilience of a subtropical monsoon evergreen broad-leaved forest in southern China. Glob Chang Biol 19:1197-1210

Zhou G, Houlton BZ, Wang W, Huang W, Xiao Y, Zhang Q, Liu S, Cao M, Wang X, Wang S (2014) Substantial reorganization of China's tropical and subtropical forests: based on the permanent plots. Glob Chang Biol 20:240-250

Publisher's note Springer Nature remains neutral with regard to jurisdictional claims in published maps and institutional affiliations. 